\title{
Pleomorphic Adenoma in Ectopic Salivary Tissue of the Neck
}

\author{
Domenico Testa ${ }^{*}, 1$, Stefania Staibano ${ }^{3}$, Germano Guerra ${ }^{3}$, Massimo Mascolo ${ }^{3}$, Francesco Galera ${ }^{2}$, \\ Renata Iovine $^{2}$ and Assunta Vassallo ${ }^{2}$
}

\author{
${ }^{I}$ Department of Head and Neck Pathology, Second University of Naples, Italy \\ ${ }^{2}$ Department of Head and Neck Surgery, University of Naples "Federico II", Italy \\ ${ }^{3}$ Department of Biomorphological and Functional Sciences, University of Naples "Federico II", Italy
}

\begin{abstract}
Introduction: The presence of salivary heterotopic tissue is uncommon and even more rarely neoplasms arise from aberrant salivary gland tissue. The finding of a benign mixed tumour (pleomorphic adenoma) in heterotopic salivary tissue along the anterior border of the sternocleidomastoid muscle, in the upper neck, is extremely rare.

Case Report: We present the fourth case - in adults patients- of ectopic mixed salivary tumour occurring in the upper neck, with regard to clinical and histological features, diagnostic aspects in relation with clinical and radiological investigations and therapeutic considerations.

Conclusion: Caution must be taken in the diagnosis and treatment of the neck masses, which often present unexpected pathology to the head and neck surgeon.
\end{abstract}

Keywords: Heterotopic salivary tissue, pleomorphic adenoma.

\section{INTRODUCTION}

Salivary gland tumours occurring in ectopic sites constitute a particular and poorly understood group of lesions, whose diagnosis is often late; heterotopic islands of aberrant salivary gland tissue may be found in the hypophysis, external auditory canal, middle ear, mastoid bone, tongue, tonsils and tonsillar fossae, in the capsule of the thyroid and parathyroid gland, in the lymph-nodes [1-4]. The presence of salivary heterotopic tissue is rather uncommon and even more rarely neoplasms arise from aberrant salivary gland tissue $[2,5,6]$. The finding of a benign mixed tumour in heterotopic salivary tissue along the anterior border of the sternocleidomastoid muscle, in the upper neck, is extremely rare. A comprehensive review of the literature shows that only four cases of ectopic mixed salivary tumours in the upper neck have been found in children and only three cases in adult patients $[2-4,7,8]$.

We present another case of ectopic mixed salivary tumour occurring in the upper neck, with regard to histological and clinical features, diagnostic aspects in relation with clinical and radiological investigations and therapeutic considerations.

\section{CASE REPORT}

R.F., a 29-year-old Italian woman, was admitted to our hospital on September 2003 complaining of a painful enlarging lump in the upper neck, which she had first noticed one year before. There were no other symptoms, no clinical evidences or family history. On physical examination the mass was located in the right anterior triangle of the neck, $2 \mathrm{~cm}$

*Address correspondence to this author at the Department of Head and Neck Pathology, Second University of Naples, Via F. Turati n. 83 - 81100 Caserta, Italy; Fax: 0823 354922; E-mail: domenictesta@libero.it below the angle of the right mandible, lying on the anterior border of the right sternocleidomastoid muscle. The lesion was firm, painful, movable on superficial plans but adherent to deeper structures.

Ultrasonic examination of the neck, performed with a 10 $\mathrm{MHz}$ probe, showed in the right anterior triangle, along the anterior border of the sternocleidomastoid muscle, a $3 \mathrm{~cm}$, hypoechoic mass with well-defined borders (Fig. 1). Neck C.T. with iodate contrast medium showed in the right anterior triangle, $2 \mathrm{~cm}$ below the angle of the mandible, a welldefined solid mass, dissociable from adjacent muscular and vascular structures (Fig. 2); the lesion was not related to the parotid gland. Fine-needle aspiration cytology (FNAC) was not diagnostic.

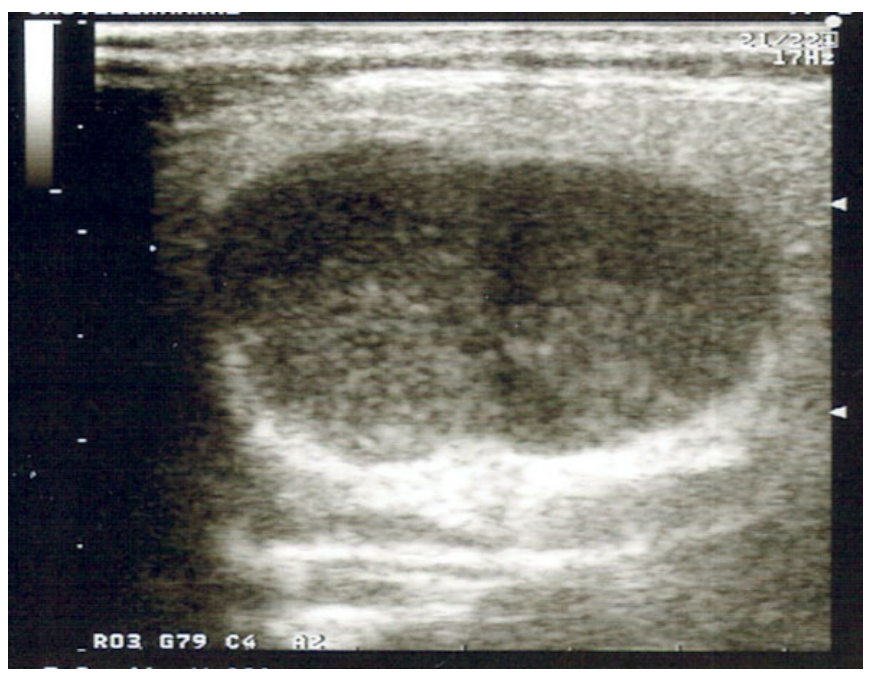

Fig. (1). Ultrasonic examination showed in the right anterior triangle, along the anterior border of the sternocleidomastoid muscle, a 3 $\mathrm{cm}$, hypoechoic mass with well-defined borders. 


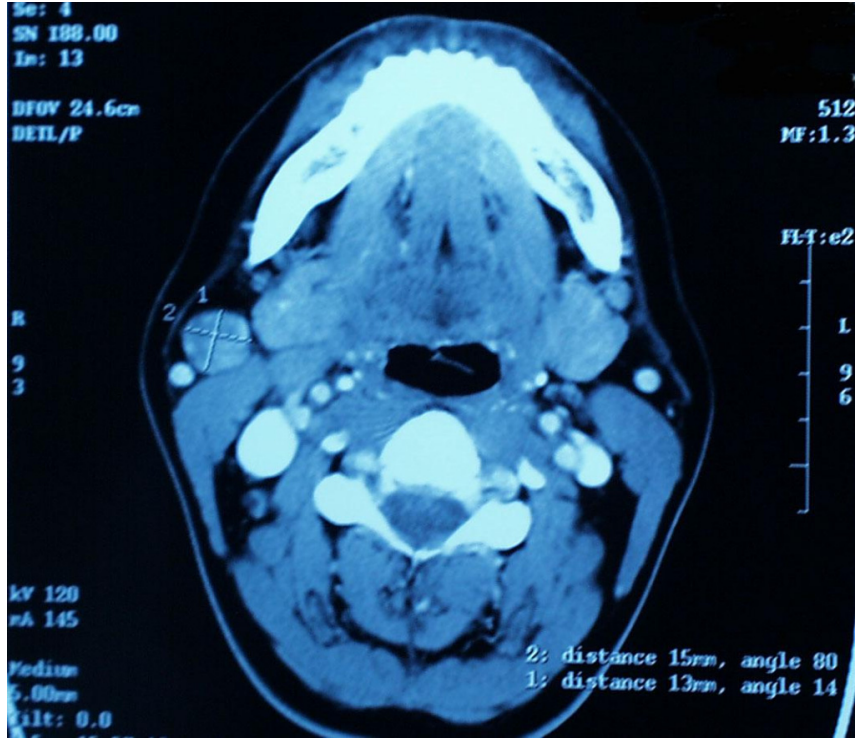

Fig. (2). Neck C.T. with iodate contrast medium showed in the right anterior triangle, $2 \mathrm{~cm}$ below the angle of the mandible, a welldefined solid mass, dissociable from adjacent muscular and vascular structures.

At operation, under general anesthesia, the lesion was completely excised. The histopathological diagnosis was pleomorphic adenoma of salivary gland (Fig. 3a,b).

The post-surgical course was normal and the patient was discharged three days later. There is no sign of local or distant recurrence three years after first operation.

\section{DISCUSSION}

Apart from the three major salivary glands, salivary tissue is normally found in the minor salivary glands within the tongue, around the tonsils, associated with the hard and soft palates, on the lips and cheeks.

Salivary heterotopia occurs only when salivary gland tissue is found in places where it is not normally present [2] ; in the literature cases of ectopic salivary glands have been recorded as far back as 1789 [3].

Various suggestions have been put forward to explain the embryological basis for this condition. Probably the best theory is that of Youngs and Schofield suggesting that the salivary heterotopic tissue in the neck is due to epithelial remnants from the branchial apparatus. More specifically, it is due to a defective closure of the pre-cervical sinus of His with internal heteroplasia [3,9]. In early embryonic life the head shows, in its ventral and lateral part, five branchial arches. The latter are separated each other by an ectodermic sulcus, the branchial sulcus, where corresponding evaginations of the branchial intestine are located (branchial pouches). The growth of the arches is not homogeneous since the first one (mandibular arch) and the second one (hyoid arch) rise more than others. The ectodermic inlet between the first two arches and the others is called cervical sinus and is externally connected by a fissure (cervical fissure). Such fissure will close and consequently the sinus will change in cervical vesicle. The latter, laterally applied to the third branchial pouch, is connected, by ducts, to the second and fourth pouches. The cervical vesicle normally closes at the end of the second uterine month; its defective closure with internal heteroplasia seems to be the possible pathogenesis of ectopic tissue in the neck.

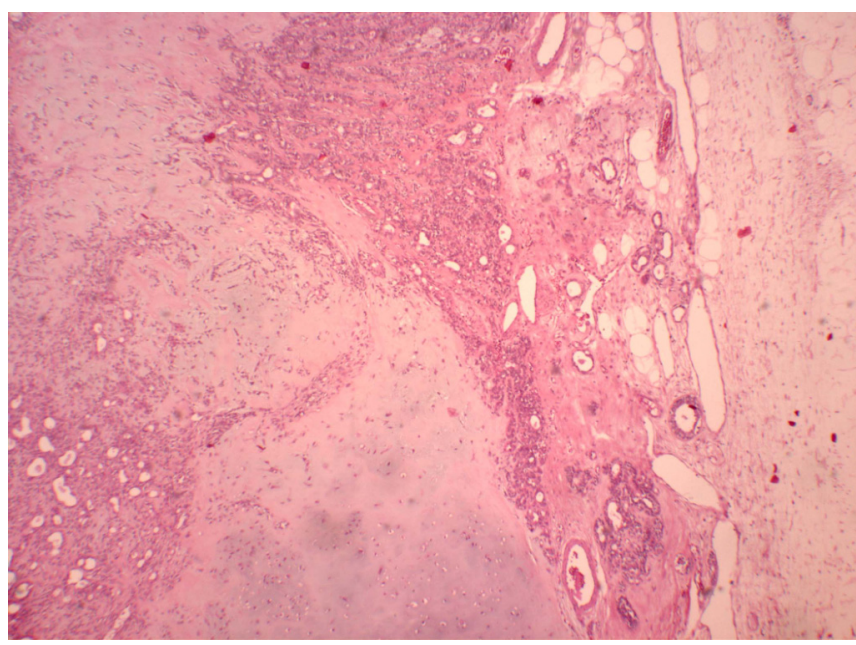

Fig. (3a). The lesion is composed of benign epithelial and mesenchymal elements. (LSAB technique, original magnification: 106x).

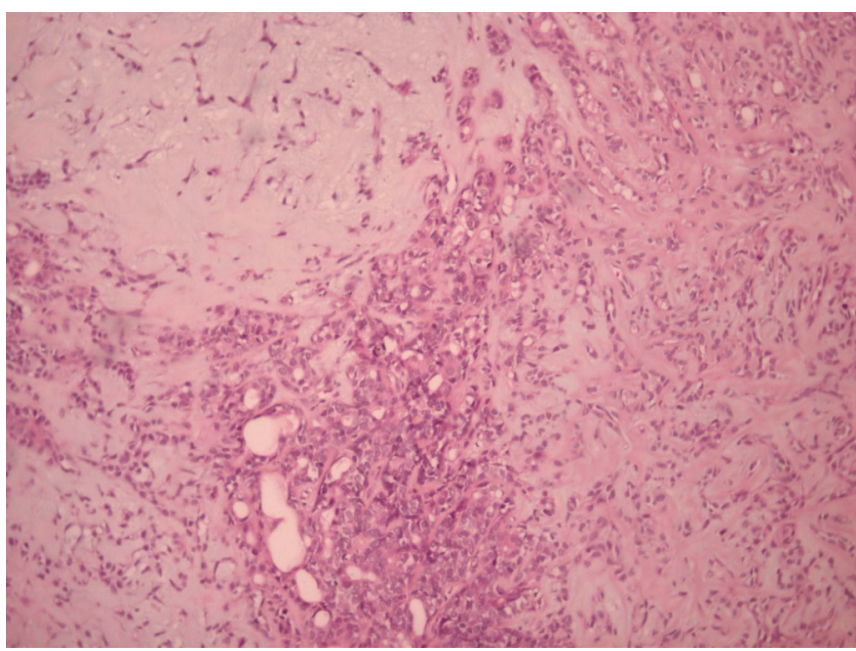

Fig. (3b). The mesenchymal component is often mixomatous and/or cartilagineous (LSAB technique, original magnification: 150x).

The presence of salivary heterotopic tissue in the neck has been widely reported in the literature, but the finding of salivary ectopic tissue along the anterior border of the sternocleidomastoid muscle, in its upper third, is extremely rare $[2,3,10]$

Apart from its unusual site, the occurrence of a benign mixed tumour in heterotopic salivary gland adds the interest of our case [5].

A wide variety of benign lesions (Warthin's tumor, pleomorphic adenoma), and malignant neoplasms (mucoepidermoid carcinoma, acinic cell carcinoma, anaplastic carcinoma) may arise in ectopic salivary gland tissue. Mixed salivary tumours are the most frequent in those ectopic neoplasm; they have the same percentage of recurrence but a higher percentage of cancerization than those occurring in the major salivary glands $[1,11]$.

A comprehensive review of the literature showed that our case of ectopic mixed salivary tumour in the upper neck in an adult patient is the fourth one to be reported. The first 
case of such tumour occurring in the neck was described by Pesavento and Ferlito in 1976 [2]; two years later Hulbert published the second case [3], followed by the third one reported by Ordonez et al. in 1994 [4].

The treatment for ectopic mixed salivary tumour endorsed by all authors is the complete surgical excision. Some authors suggest a post-operative radiotherapy as a prophylactic measure $[1,11]$.

In our case the patient did not need to undergo radiotherapy due to the radical surgical procedure and the benign histological finding.

\section{REFERENCES}

[1] Ross DE, \& Sukis AE. Salivary gland tumors in ectopic sites. Laryngoscope 1971; 81: 558-64.

[2] Pesavento G, \& Ferlito A. Benign mixed tumour of heterotopic salivary gland tissue in upper neck. Report of a case with a review of the literature on heterotopic salivary gland tissue. J Laryngol Otol 1976; $90: 577-84$.
[3] Hulbert JC. Ectopic mixed salivary tumour in the neck. J Laryngol Otol 1978; 92: 533-6.

[4] Ordonez MM, Sancho Alvarez A, Morais Perez D, Alvarez Gago T. Mixed tumour in cervical salivary heterotopy. Acta Otorrinolaringol. Esp 1994; 45: 387-9.

[5] Batsakis JG. Tumors of the head and neck. Williams and Wilkins: Baltimora; 1974.

[6] Cotelingam JD, Gerberi MP. Parotid heterotopia with pleomorphic adenoma. Arch Otolaryngol 1983; 109: 563-5.

[7] Surana R, Moloney R, Fizgerald RJ. Tumours of heterotopic salivary tissue in the upper cervical region in children. Surg Oncol 1993; 2 : 133-6

[8] Claros P, Turcanu D, Claros A. Jr, Vila Torres J. Pleomorphic adenoma in ectopic salivary tissue in a child. Acta Otorrinolaringol Esp 2000; 5: 543-7.

[9] Youngs LA, Schofield HH. Arch Pathol 1967; 83: 550

[10] Gaillard de Collogny L, Delage J, Lafaye M, Brauchli G, Boutet JJ. Mixed salivary gland tumours at unusual locations or ectopic. J French Otorhinolaryngol. Audiophonol. Chir. Maxillofac 1979; 28: 519-29.

[11] Caironi CS, Canali RE, Canali B. Tumore misto a carico di ghiandola salivare ectopica. Minerva Chirurgica, 1981; 36: 621-4. 